\title{
Analytical evaluation of energy efficiency potential enhancement of heat-generating units by flow variation in the boiler circuit
}

\author{
Pavel A. Artamonov ${ }^{1,}$, Nikolai I. Kurilenko ${ }^{1}$, and Gennady Ya. Mamontov ${ }^{2}$ \\ ${ }^{1}$ Tyumen State Industrial University, 625000 Tyumen, Russia \\ ${ }^{2}$ National Research Tomsk Polytechnic University, 634050 Tomsk, Russia
}

\begin{abstract}
Three-dimensional models of the most common boiler schemes are developed and the hydraulic characteristic of each scheme is built. The calculation results of the main technical and economic indicators of the schemes are done. They are energy, metal consumption, capital costs and operating costs. According to the results of the analysis, there is a technical solution to reduce the energy consumption of the boiler circuit pumping equipment. The complex evaluation of the options in the context of the boiler manufacturer and operation is made, the investment attractiveness is calculated.
\end{abstract}

\section{Introduction}

Nowadays the great attention is paid to the energy saving and energy efficiency enhancement. All over the world the laws, strategies and programs are passed to stimulate the energy conservation. Due to the necessity of the energy resources efficient use, new technologies are developed, the energy saving equipment is implemented and this results in energy saving [1]. One of the initial stages of heat-generating units is a selection of the basic operation circuit. Optimization of thermal and hydraulic conditions inside the heatgenerating units is one of the ways to enhance the energy efficiency [2]. The terms of a heat-generating unit and a boiler station are equal in this work.

\section{Problem statement an solution methods}

Let us consider two most widespread types of boiler circuits of the heat-generating units that use an independent heating scheme. These types will be examined in terms of the boiler heat capacity that is 9 Mega Watts (three KCB-3,0 boilers produced by "MAXTHERM") with a HH-62-16/3-167- TKTM32 plate heat exchanger produced by "Ridan" (heating system circuit) and a HH-42-16/1-33-TKTM25 plate heat exchanger produced by "Ridan" (hot-water supply system circuit) that are 6 and 3 Mega Watts

\footnotetext{
* Corresponding author: P.Artamonovv@,yandex.ru
} 
respectively. The temperature in the boiler circuit delivery pipeline is $105{ }^{\circ} \mathrm{C}$, in the return one $-80{ }^{\circ} \mathrm{C}$.

The first type is a boiler circuit with pumps that are immediately near each boiler at the return pipeline (fig. 1a). In this case, each pump operates together with a boiler and turns on under its start-up conditions. The boilers are operated in a cascade mode and the amount of the supplied heat is controlled by triple valves (condition 5).

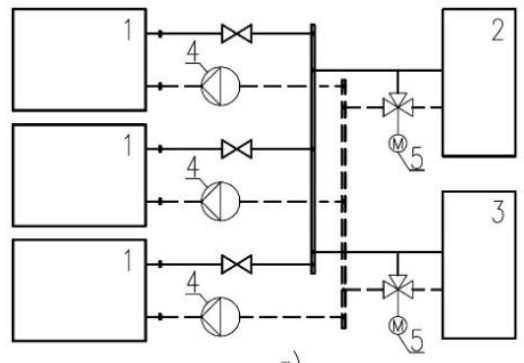

a)

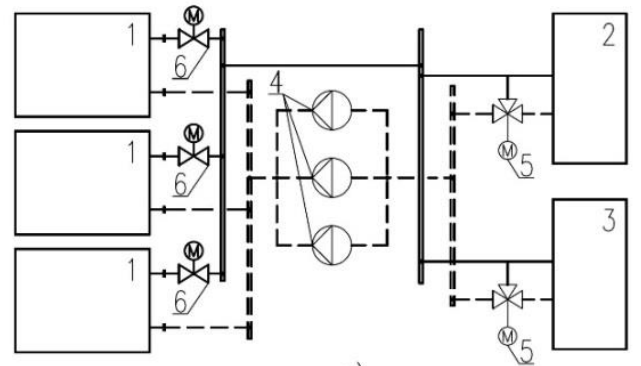

0)

Fig. 1. The basic boiler circuit: a - type $1, \mathrm{~b}$ - type 2.1 - boiler having a capacity of 3 Mega Watts; 2 - heat exchanger of the heating system; 3 - heat exchanger of the hot-water supply system; 4 - boiler circulation pump; 5 - triple valve; 6 - motor-operated valve.

In the second type, the boiler capacity and the amount of the supplied heat are controlled in a similar way as in the first one, but the boiler pumps are installed at the return pipeline (fig. 1b). To avoid the coolant circulation via an idle boiler, an electrical motor operated valve is provided (condition 7).

To carry out an overall comparison, the authors have developed two 3D boiler circuit models of the heat-generating units (fig. 2,3) that correspond to the schemes shown in figure 1 .

Based on the developed models the authors have analyzed each scheme in three basic operation modes:

- mode No 1 - one boiler is in use;

- mode No 2 - two boilers are in use;

- mode No 3 - three boilers are in use.

Each mode corresponds to a certain heat rate in the boiler circuit. If the predetermined temperature difference at the return and delivery pipeline is $25^{\circ} \mathrm{C}$, the mean heat capacity of a heat transfer agent equals $4,19 \mathrm{~kJ} / \mathrm{kg}$ and a density is $963,85 \mathrm{~kg} / \mathrm{m}^{3}$, the heat rate in the boiler circuit in operation modes No 1, 2, 3 will be equal to $103,206,309 \mathrm{~m}^{3} / \mathrm{h}$ respectively.

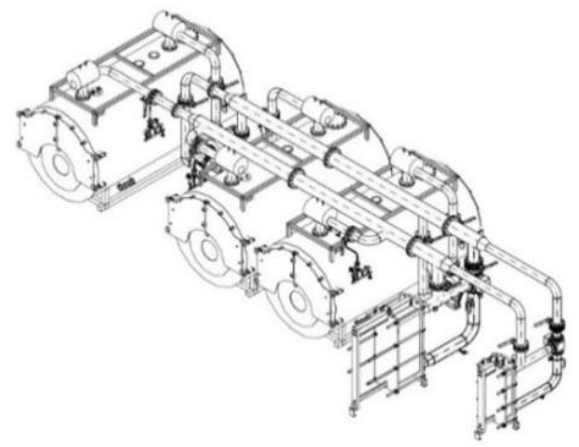

Fig. 2. 3D model developed according to the basic scheme of the first type.

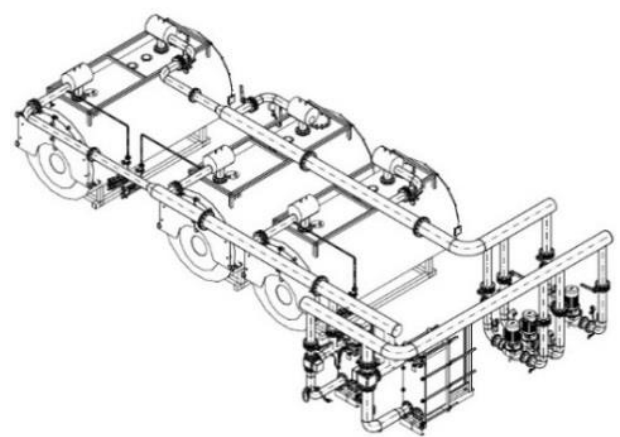

Fig. 3. 3D model developed according to the basic scheme of the first type. 
The friction pressure loss was calculated by Darcy - Weisbach's equation, the restriction losses were determined by Weisbach's equation [3]. The local loss coefficients are specified according to [4]. Equipment losses (gate valves, nonreturn and triple valves, air collectors, etc.) were determined on the basis of the flow factor mentioned in the test certificate. The pumping machinery selection was carried out based on the hydraulic design findings (see Table 1).

Table 1. Hydraulic design findings.

\begin{tabular}{|c|c|c|c|c|}
\hline & \multicolumn{3}{|c|}{ Pressure losses, w.c.m. } & \multirow{2}{*}{ Pump } \\
\cline { 2 - 4 } & Mode No 1 & Mode No 2 & Mode No 3 & \multirow{2}{*}{ WILO BL 125/185-5,5/4 } \\
\hline Type 1 & 8.77 & 9.34 & 9.94 & WILO IL 125/210-5,5/4 \\
\hline Type 2 & 9.14 & 9.7 & 10.77 & . \\
\hline
\end{tabular}

The main purpose of the energy efficient operation of the heat-generating units is a fine control of the generated heat amount [5]. The authors have calculated the consumed heat rate throughout the year at the average monthly temperature of Tyumen outside air by the procedure set in design and construction specifications 41-104-2000 "Design of independent heat supply sources". Based on the findings the boiler operation in various year periods is determined. From April to October the boiler operates in mode No 1 to provide the necessary heat amount to consumers. From October to March - in mode No 2. The boiler operates in mode No 3 to provide the boiler peak load. The power control of the boiler thermal rating is done by the flame modulation in the burner, and the supplied heat is controlled by the triple valve. Based on the annual heat consumption value, the annual energy consumption was calculated. For the first type ("a" fig. 1) it is $64215,43 \mathrm{kWh}$, for the second one ("b" fig. 1) - 68791,9 kWh. The higher energy consumption of the second type is connected to the distinctive features of pipelining (see Table 1). Thus, the boiler circuit scheme of the second type is characterized by high energy consumption and a high maintenance cost as well.

As it was aforementioned, the boiler thermal rating is controlled by the flame modulation. In other words, when the heat-generating unit operates in the first mode and the power is controlled by the flame modulation from 40 to $100 \%$, the boiler efficiency can vary from 1200 to 3000 kilowatt. Therewith, the heat rate is fixed regardless of the burner capacity. It means that if we neglect the pump operating point fluctuations when the triple valve position changes, we can state that the boiler pump energy consumption is fixed in each operation mode.

The future oriented way to reduce the pump unit energy consumption and thus, the maintenance cost reduction is a coolant rate control in the boiler circuit by the rotation frequency change of the pump rotor when the number of pump motor axis rotations is changed $[6,7,8]$.

The authors suggested the boiler circuit operation scheme with the pump variablefrequency control (type 3). This scheme is different from the second type by the flow rate meter (condition 9), temperature detectors (condition 7) and a frequency converter (fig. 4). 


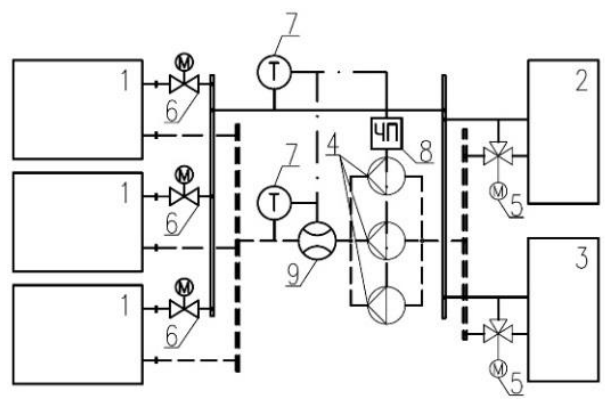

Fig 4. Boiler circuit basic scheme with the pump variable-frequency control. 1, 2, 3, 4, 5, 6 similar to figure $1 ; 7$ - temperature detector; 8 - frequency converter; 9 - flow rate meter.

The $3 \mathrm{D}$ model is similar to the second type apart from the flow rate meter (see fig. 3). Based on the hydraulic design findings, the IL 100/220-5,5/4 pump produced by "Wilo" was selected. The more express pump was selected in terms of the pressure resistance in the boiler circuit when the flow rate meter is implemented.

The pump motor rotation frequency change is carried out in the following way: the heatgenerating unit controller calculates the required boiler heat rate value in virtue of the coolant parameters of the line-operated circuit and a temperature dependence diagram of the delivery pipeline as it leaves the heat-generating unit on the outside air temperature. Based on the flow rate meter (condition 9) and temperature detector (condition 7) findings, the controller calculates the real value of the boiler heat rate. The differential of these values must be close or equal to zero. If the differential is higher than zero, i.e. the value of the supplied heat energy is higher than the target one, the controller sends out a signal to reduce the pump motor rotation frequency. If the differential is lower than zero, the frequency converter receives the signal to increase the frequency. To avoid the flow rate ramp change, the control logic should include the proportional integral derivative controller $[9,10]$. Concurrently, it is necessary to control the boiler thermal rating and its cascading. The target value of the temperature differential is constant at the detectors (condition 7). Otherwise, the pumps will balance the low temperature differential by the flow rate increase that leads to the excess demand energy.

\section{Results and discussion}

The developed algorithm of the boiler circuit control of the heat-generating units allowed scaling the coolant flow rate and the consumer heat load change at a specified value of the temperature differential that is $25{ }^{\circ} \mathrm{C}$ at the delivery and return pipeline. The energy consumption was calculated on the ground of the average monthly heat consumption values (fig. 5). The annual energy consumption for the third type is $21264 \mathrm{kWh}$. The obtained results show that the boiler circuit operation allows reducing the annual energy consumption by a factor of 3,23 (by $47527,9 \mathrm{kWh}$ ) over the second type and by a factor of 3,02 (by 42951,43 kWh) over the first type. 


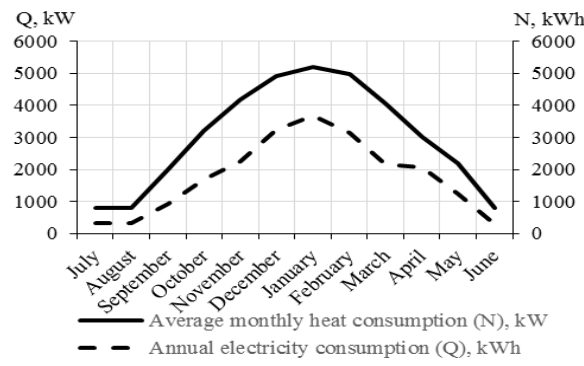

Fig. 5. Consumed heat and electric energy.

To evaluate all studied types of the boiler circuit operation of the heat-generating units the investment prospects will be analyzed. To calculate the capital costs the authors considered only the component and material cost of the boiler circuit manifold. Other capital cost items (wiring cost, transport charges, procuring and storage charges, etc.) are equal for all types and that allows neglecting them. The capital investments and capital energy costs consumed by pumps are presented (when one of the three types of the boiler circuit is implemented) in Table 2 . The electricity tariff is $2,5 \mathrm{rub} / \mathrm{kWh}$.

Table 2. Comparison of the critical parameters.

\begin{tabular}{|c|c|c|c|}
\hline Parameters & Type 1 & Type 2 & Type 3 \\
\hline Capital costs, RUB, in thousands & 781.78 & 972.19 & 1000.94 \\
\hline $\begin{array}{c}\text { Energy costs, consumed by boiler pumps, RUB, in } \\
\text { thousands /year }\end{array}$ & 160.54 & 171.98 & 53.16 \\
\hline $\begin{array}{c}\text { Specific quantity of metal per structure, kg/ Mega } \\
\text { Watts }\end{array}$ & 210.47 & 256.1 & 259.82 \\
\hline Pay-back period, year & 2 & 2.3 & 2.13 \\
\hline
\end{tabular}

The calculation results show that the pay-back period for the heat-generating unit operation of 1, 2 and 3 type is 2, 2,3 and 2,13 years respectively. After a year from the date of operation even if the capital costs are the highest (see Table 2) the third type will exceed the consolidated profits obtained when the second type is used and in three years it becomes the most profitable of all studied types of the boiler circuit operation.

\section{Conclusion}

Analysis of the suggested method to change the flow rate showed the high potential to reduce the energy consumption of the heat-generating units and is the most investment attractive.

The models studied in this work provide insight into the overall perspectives of the flow rate proportional change in heat-generating units. Despite the high potential of energy saving, the use of the suggested method should be based on the detail analysis as the reduction in heat-generating unit capacity leads to the reduction of the total value of the saved physical resources and to the pay-back period change.

The work was supported by the Russian President's grant (Scientific School project 7538.2016.8).

\section{References}

1. B.M. Nizameev, Bulletin of St PbSIT(TU), 34, 97 (2016) [In Russian] 
2. S.B.Nekhoda, Plumbing system, heating, air-conditioning, 2, 110 ( 2011) [In Russian]

3. A.D. Altshul, Hydraulics and aerodynamics (Stroyizdat, Moscow, 1965) [In Russian]

4. I.G. Staroverov, Sanitary-engineering installations (Stroyizdat, Moscow, 1990) [In Russian]

5. A.M. Suleimanov, Ufa state oil technical university, 381 (2016) [In Russian]

6. A.V. Kozhukhova, Bulletin of Voronezh state technical university , 11-3, 95-97 (2016) [In Russian]

7. J. Bujak, Energy, 34, 1260-1270 (2009)

8. F.A.Amirov, Equipment and technologies for oil and gas complex, 4, 34-35 (2012) [In Russian]

9. J.Quevedo, T.Escobet, Proceedings of the IFAC Workshop, Eds. Terrassa, 5, 618 (2000)

10. K.J. Strom, T. Hagglund, Advanced PID control (ISA - The Instrumentation, Systems, and Automation Society, 2006)

11. P.N. Kamenev, E.I. Tertichnik, Ventilation system: study guide (ASV, Moscow, 2008) [In Russian] 